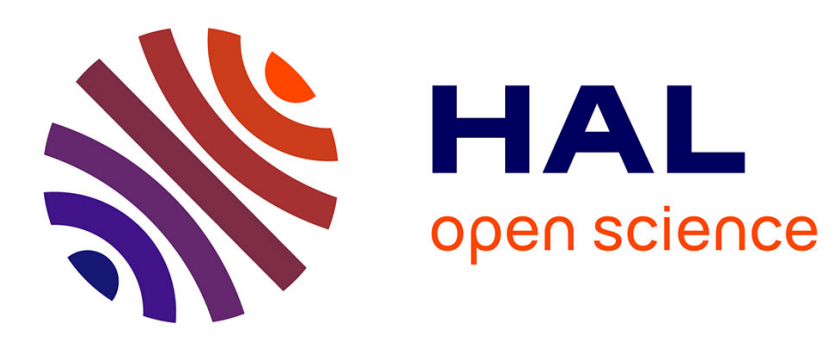

\title{
On the typical spectral shape of an economic variable
}

\author{
Daniel Levy, Hashem Dezhbakhsh
}

\section{To cite this version:}

Daniel Levy, Hashem Dezhbakhsh. On the typical spectral shape of an economic variable. Applied Economics Letters, 2003, 10 (7), pp.417-423. 10.1080/1350485032000102187 . hal-02386554

\section{HAL Id: hal-02386554 https://hal.science/hal-02386554}

Submitted on 29 Nov 2019

HAL is a multi-disciplinary open access archive for the deposit and dissemination of scientific research documents, whether they are published or not. The documents may come from teaching and research institutions in France or abroad, or from public or private research centers.
L'archive ouverte pluridisciplinaire HAL, est destinée au dépôt et à la diffusion de documents scientifiques de niveau recherche, publiés ou non, émanant des établissements d'enseignement et de recherche français ou étrangers, des laboratoires publics ou privés. 


\title{
On the Typical Spectral Shape of an Economic Variable
}

\author{
Daniel Levy* \\ Bar-Ilan University and Emory University \\ and \\ Hashem Dezhbakhsh**§ \\ Emory University
}

Last Revision: September 2002

Forthcoming 2003

JEL Classification Code Numbers: E32, O40, O57.

Key Words: Spectral Analysis, Spectral Shape, Output Level, OECD, and Developing Countries.

* Contact Information: Daniel Levy, Department of Economics, Bar-Ilan University, Ramat-Gan 52900, Israel, Tel. (972-3-) 531-8331; e-mail: Levyda@ mail.biu.ac.il.

** Contact Information: Hashem Dezhbakhsh, Department of Economics, Rich Building, 1602 Mizell Drive, Emory University, Atlanta, GA 30322-2240, U.S.A. Tel. (404) 727-4679; e-mail:

Econhd@emory.edu.

$\S$ Corresponding author. 


\title{
On the Typical Spectral Shape of an Economic Variable
}

\begin{abstract}
In a classic article, Granger (1966) asserted that most economic time series measured in level have spectra that exhibit a smooth declining shape with considerable power at very low frequencies. There has been no systematic attempt to examine Granger's assertion with international data. We estimate output level spectra for 58 countries, divided into developed, high-income developing, and lowincome developing groups. We find the shapes of the estimated spectra to be strikingly similar to Granger's typical shape, particularly for the developed countries.
\end{abstract}




\section{Introduction}

Spectral methods are used increasingly to uncover the characteristics of economic time series. In particular, the shape of spectra has important implications for economic theory and model building. In a pioneering work in this area, Granger (1966) identifies, what he terms, "the typical spectral shape" for economic series measured in level. Accordingly, the spectral mass is concentrated mostly at low frequencies, declining exponentially and smoothly as the frequency increases. Stating these characteristics more formally, he offers the following law:

"The long-term fluctuations in economic variables, if decomposed into frequency components, are such that the amplitude of the components decrease smoothly with decreasing period" (Granger, 1996, p. 155).

Granger emphasizes that any peak of the spectrum of level series is at a very low frequency, and that the spectrum does not include peaks of decreasing size corresponding to cycles of different lengths. The spectral shape also exhibits robustness as Granger argues:

"Moreover, the same basic shape is found regardless of the length of data available, the size of the truncation point used in the estimation procedure, or the trend removal method used" (Granger, 1996, p. 154).

Granger bases his assertion on sporadic evidence on few economic series reported earlier. To the best of our knowledge there has been no attempt to examine Granger's assertion using international data. We examine the spectra of output level series for 58 countries, separated into developed (OECD), high-income developing, and low-income developing groups. Given that an important 
objective of economic policy is to smooth out cyclical fluctuations in the output level without affecting the output trend, it is interesting to see if the power spectra suggest a successful accomplishment of this policy objective. The typical shape is consistent with such a scenario. We find that, with few exceptions, the spectra of level series exhibit the typical shape that Granger identifies. The similarity is particularly remarkable for the developed countries.

In the remaining sections, we discuss the econometric method, present the empirical findings on the spectral shape of the level series, and briefly discuss some implications.

\section{Econometric Method}

Spectral analysis provides a powerful tool for studying the behavior of economic time series. (See, e.g., Granger and Hatanaka (1964), Priestly (1981), Granger and Watson (1984), Koopmans (1995), Baxter and King (1995), and King and Watson (1996).) Unlike the standard time domain analysis, which implicitly assigns all frequencies equal weight, or restricts the analysis to a limited set of frequencies, the spectral analysis is conducted on a frequency-by-frequency basis, using the entire frequency range 0 to $\pi$. For univariate series, the method identifies how much of the series total variance is determined by each periodic (frequency) component.

More specifically, the spectrum of a series $y_{t}$ is defined as the Fourier transform of its

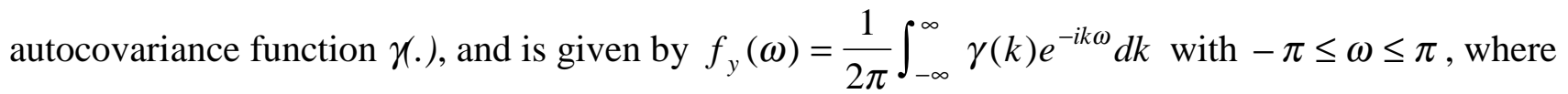
the frequency $\omega$ is measured in cycles per period (in radians). Since $f_{y}(\omega)$ is symmetric about $\omega=0$ it is customary to limit the analysis to the frequency interval $0 \leq \omega \leq \pi$. The spectrum of a series decomposes its total variation by the cycle-length of various periodic components. 
Following a common practice in macroeconomic applications of spectral analysis, we divide the frequency interval into three segments: long-run frequency band, business cycle frequency band, and short-run frequency band. For example, Prescott (1986) defines business cycles as three to eight year cycles. Similar cutoff points are used by Granger and Hatanaka (1964), Lucas (1980), Summers (1980), Zarnowitz (1992), Levy (1994), Levy and Chen (1994), Carpenter and Levy (1998), Levy (2000), and Dezhbakhsh and Levy (2003). Accordingly, the cut-off points that we choose are $0 \leq \omega \leq 0.785$ for the long-run (LR) frequency band, $0.785 \leq \omega \leq 2.09$ for the business cycle (BC) frequency band, and $2.09 \leq \omega \leq \pi$ for the short-run (SR) frequency band. Since we use annual data, these frequency intervals correspond to cycles that are longer than eight years, three to eight years, and shorter than three years, respectively.

An additional feature usually emphasized in spectral analysis is the presence of peaks in the spectrum, which indicate that periodicities are present in the time series. The exact location of the peak in the $(0, \pi)$ range identifies the cyclical component with the most substantial contribution to the series variation. For example, a spectral peak in the business cycle frequency range $0.785 \leq \omega \leq 2.09$, suggest that business cycles contribute to much of the series variations.

A consistent estimate of the spectrum can be obtained from the smoothed estimate of the periodogram of the time series. The smoothing, which is done to achieve consistency of the spectrum estimate, is accomplished by taking weighted integral of the periodogram's ordinates. Several weight structures, also called lag windows, have been proposed in the literature. The main difference between them is in the way they generate the weights. We smooth the periodograms estimates using three lag windows (Bartlett's, Tukey's, and Parzen's). They all yield very similar results; we, therefore, report the estimates using Bartlett's window, which assigns linearly decreasing weights to the autocovariances in the neighborhood of the frequencies considered and zero weight thereafter. 
Accordingly, we estimate $f\left(\omega_{j}\right)$ where $\omega_{j}=j \pi / m$ and $j=0,1,2, \ldots, m$. The number of ordinates, $m$, is set using the rule $m=2 \sqrt{\text { sample size }}$, as suggested by Chatfield (1989, p. 115).

To obtain the variance of the estimated spectra, and thus the corresponding confidence intervals, we use the fact that the estimate of the spectrum at frequency $\omega, \hat{f}(\omega)$ is approximately distributed as a $\chi_{v}^{2} / v$ variate, where $v=3($ sample size) $/ m$ (Fuller, 1976, p. 296).

\section{Data, Results, and Implications}

Our data source is the International Financial Statistics tape of the IMF. The annual data set covers 58 countries over the period $1950-94$. We chose to work with annual data so as to cover the same time period for all countries, thereby facilitating a cross-country comparison of our results; as emphasized by Campbell and Mankiw (1989), quarterly data covering the same time span are not available for many countries. A drawback of annual data is having fewer observations, which results in larger standard errors of the estimated spectra. This, however, is quite common in the literature. For example, King and Watson's (1996) and Cochrane's (1988) estimates of spectra have large standard errors. Campbell and Mankiw (1989) also report shock persistence estimates that have substantial imprecision.

Our sample includes 23 developed, 17 high-income, and 18 low-income developing countries. To categorize countries into these three groups, we rank them based on their average real per capita income. The selection criterion for the first two groups is whether a country is a member of the OECD or not. As it turns out, there is a substantial income gap between the poorest OECD member (Portugal) and the richest member of the high-income group (Trinidad and Tobago). Similarly, we 
divide the developing countries into high- and low-income groups using the substantial income gap between Guatemala and El Salvador as a "natural" break point.

Figures 1-3 display estimates of the spectra for output series measured in level. Spectral plots for developed countries are shown in Figure 1 and similar plots for high- and low-income developing countries are presented in Figures 2 and 3, respectively. We also report the corresponding ninety percent confidence intervals computed using the chi square approximation, as discussed in section 2 .

While the inspection of the estimated spectra along vertical grids reveals that confidence intervals are wider than they appear, we nevertheless note a striking similarity between most countries' output level spectra and the typical spectral shape that Granger (1966) identifies. Specifically, the spectral mass of the series is concentrated at low frequencies, declining smoothly as the frequency increases. The similarity of the spectral plots for the OECD countries (Figure 1) makes it difficult to distinguish among them. There are two important implications here. First, the location of the peak in the long run frequency band suggest that most of the variability in these countries outputs is due to the long-run component. Such variations are likely to have been caused by highly persistent shocks, which are often viewed as supply shocks (see, e.g., Blanchard and Quah (1989)). Second, the smooth shape of the estimated spectra for these countries and the relatively insignificant mass in the business cycle and short-run frequency bands suggest that short-term components contribute little to output level variations in these countries.

There is less conformity, however, among the developing countries (Figures 2 and 3). For example, four of the high-income developing countries (Venezuela, Uruguay, Mauritius, and Chile) and three of the low-income developing countries (Guyana, Uganda, and Zaire) have a spectral density that differs from Granger's typical shape. In six out of the seven cases, however, most of the

\footnotetext{
${ }^{1}$ Obviously, any statistical inference about similarity of two geometric shapes must be made with caution, particularly when the maintained (null) shape is verbally rather than mathematically defined. Only if the maintained
} 
spectral mass is still concentrated around zero-frequency band, declining as the frequency increases. Such inference does not hold true for Uganda, given the reported confidence interval. Moreover, the spectral mass for all seven countries is spread over a wider frequency range and the spectrum height at zero frequency is substantially lower in comparison to other countries. Such spreading may be due to poor quality of data. Data quality scores that Summers and Heston (1991) assign to these countries are consistent with this hypothesis (see also Dezhbakhsh, 2002). For example, Guyana, Mauritius, Uganda, and Zaire have the lowest possible scores, D; while Uruguay scores $\mathrm{C}^{-}$and Venezuela and Chile C. Alternatively, it is conceivable that short-term components such as demand shocks (Blanchard and Quah, 1989) play a more determining role in output fluctuations in developing countries and they, therefore, account for a larger portion of output level variations.

Thus, we find that the spectra of output level series for many countries suggest that "... events which affect the economy for a long period are more important than those which affect it only for a short time" (Granger, 1966, p. 155). Moreover, the scope of our finding suggests that these characteristics may be a common feature of all economies. Therefore, one way of testing the fit of a macroeconomic model is to check whether it generates output that has a spectrum with a typical spectral shape.

\section{Conclusion}

Granger (1966) identifies, what he terms "the typical spectral shape" for several U.S. macroeconomic series measured in level. We examine the frequency domain properties of output

(null) shape was mathematically specified, a statistical inference could be made using a distance measure such as Kolmogorov-Smirnov, which is commonly used to examine statistically the similarity between an empirical distribution function and a maintained (null) theoretical distribution. 
level for 58 countries, separated into developed, and high- and low-income developing groups. We find that the output spectra for most countries indeed follow closely the typical shape identified by Granger-it has a smooth declining shape with considerable power at very low frequencies. This suggests that output level variations are primarily due to long run components and shocks that are persistent.

The pattern is slightly different for some of the developing countries where the power spectra are more spread. One possible explanation is that for these countries short-term components such as demand shocks account for a larger portion of output level variations. Alternatively, poor data quality can be the source of added noise that inflates the power spectra at high frequencies. 


\section{References}

Baxter, Marianne, and Robert G. King (1995), "Measuring Business Cycles: Approximate Band-Pass Filters for Economic Time Series," National Bureau of Economic Research, Working Paper No. 5022.

Blanchard, Olivier J. And Danny Quah (1989), "The Dynamic Effects of Aggregate Demand and Supply Disturbances," American Economic Review, Volume 79, Number 4 (September), 655-73.

Campbell, John Y. and N. Gregory Mankiw (1989), "International Evidence on the Persistence of Economic Fluctuations," Journal of Monetary Economics, Volume 23, Number 2 (March), 319-333.

Carpenter, Robert E. and Daniel Levy (1998), "Seasonal Cycles, Business Cycles, and the Co-movement of Inventory Investment and Output," Journal of Money, Credit, and Banking, Volume 30, Number 3, Part I (August), 331-346.

Chatfield, C. (1989), The Analysis of Time Series (London: Chapman and Hall).

Cochrane, John (1988), "How Big is the Random Walk in GNP?" Journal of Political Economy, Volume 96, (October), 893-920.

Dezhbakhsh, Hashem (2002), "The Political Economy of Statistical Evidence: Economic Data Problems in Developing Countries and Their Impact on Empirical Research," a manuscript presented at the Conference on Development Issues in the New Economy, March, Cape Town, South Africa.

Fuller, Wayne, A. (1976), Introduction to Statistical Time Series (New York: John Wiley \& Sons).

Granger, Clive W.J. (1966), “The Typical Spectral Shape of an Economic Variable," Econometrica, Volume 34, Number 1 (January), 150-161.

Granger, Clive W.J. and M. Hatanaka (1964), Spectral Analysis of Economic Time Series (Princeton, NJ: Princeton University Press).

Granger, Clive W. J. and Mark W. Watson (1984), "Time Series and Spectral Methods in Econometrics," in the Handbook of Econometrics, Volume II, Edited by Zvi Griliches and Michael D. Intriligator (New York: North Holland and Elsevier Science), pp. 980-1022.

King, Robert G. and Mark W. Watson (1996), "Money, Prices, Interest Rates, and the Business Cycle," Review of Economics and Statistics, Volume 78, Number 1 (February), 35-53.

Koopmans, Lambert H. (1995), The Spectral Analysis of Time Series (San Diego, CA: Academic Press).

Levy, Daniel (1994), “Output, Capital, and Labor in the Short and Long Run,” Southern Economic Journal, Volume 60, Number 4 (April), 946-960.

Levy, Daniel and Haiwei Chen (1994), "Estimates of the Aggregate Quarterly Capital Stock for the Post-War US Economy," Review of Income and Wealth, Series 40, Number 3 (September), 317-349.

Levy, Daniel (2000), "Investment-Saving Co-movement and Capital Mobility: Evidence from Century Long US Time Series," Review of Economic Dynamics, Volume 3, Number 1 (January), 100-136. 
Levy, Daniel and Hashem Dezhbakhsh (2003), "International Evidence on Output Fluctuation and Shock Persistence," Journal of Monetary Economics, forthcoming.

Lucas, Robert E., Jr. (1980), “Two Illustrations of the Quantity Theory of Money," American Economic Review, Volume 70, Number 5 (December), 1005-1014.

Prescott, Edward C. (1986), "Theory Ahead of Business Cycle Measurement," Quarterly Review, Federal Reserve Bank of Minneapolis (Fall), 9-22.

Priestley, M.B. (1981), Spectral Analysis and Time Series (San Diego, CA: Academic Press).

Summers, Lawrence H. (1980), "The Non-Adjustment of Nominal Interest Rates: A Study of the Fisher Effect," in Macroeconomics, Prices, and Quantities, edited by James Tobin (Washington, DC: The Brookings Institution), 201-244.

Zarnowitz, Victor (1992), Business Cycles (Chicago: University of Chicago and the National Bureau of Economic Research). 

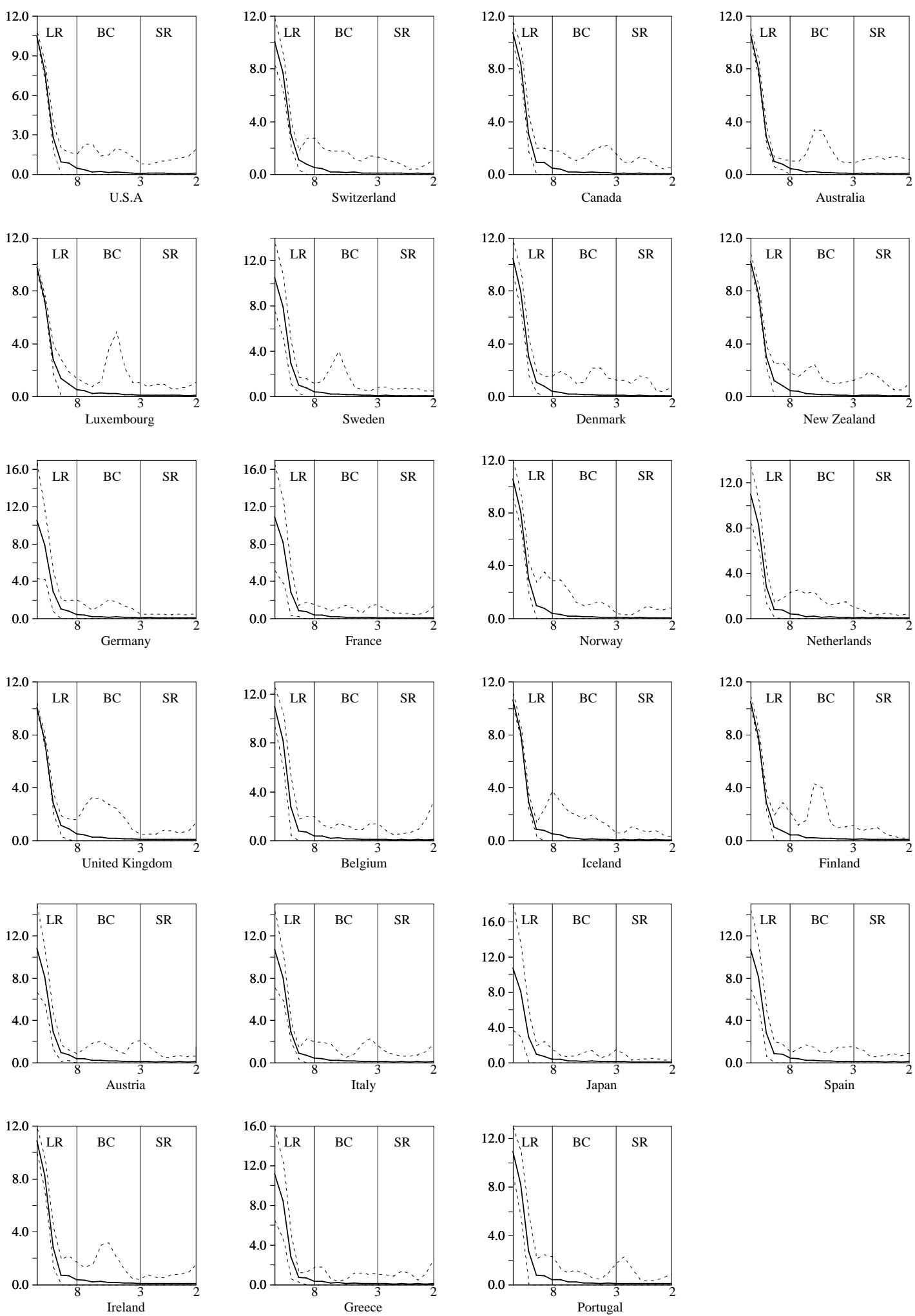

Figure 1. Estimated spectral densities of output, Developed Countries.

The horizontal axis measures the cycle-length in years.

The dotted lines form 95 percent confidence interval.

$\mathrm{LR}=$ Long Run, $\mathrm{BC}=$ Business Cycle, and $\mathrm{SR}=$ Short Run. 

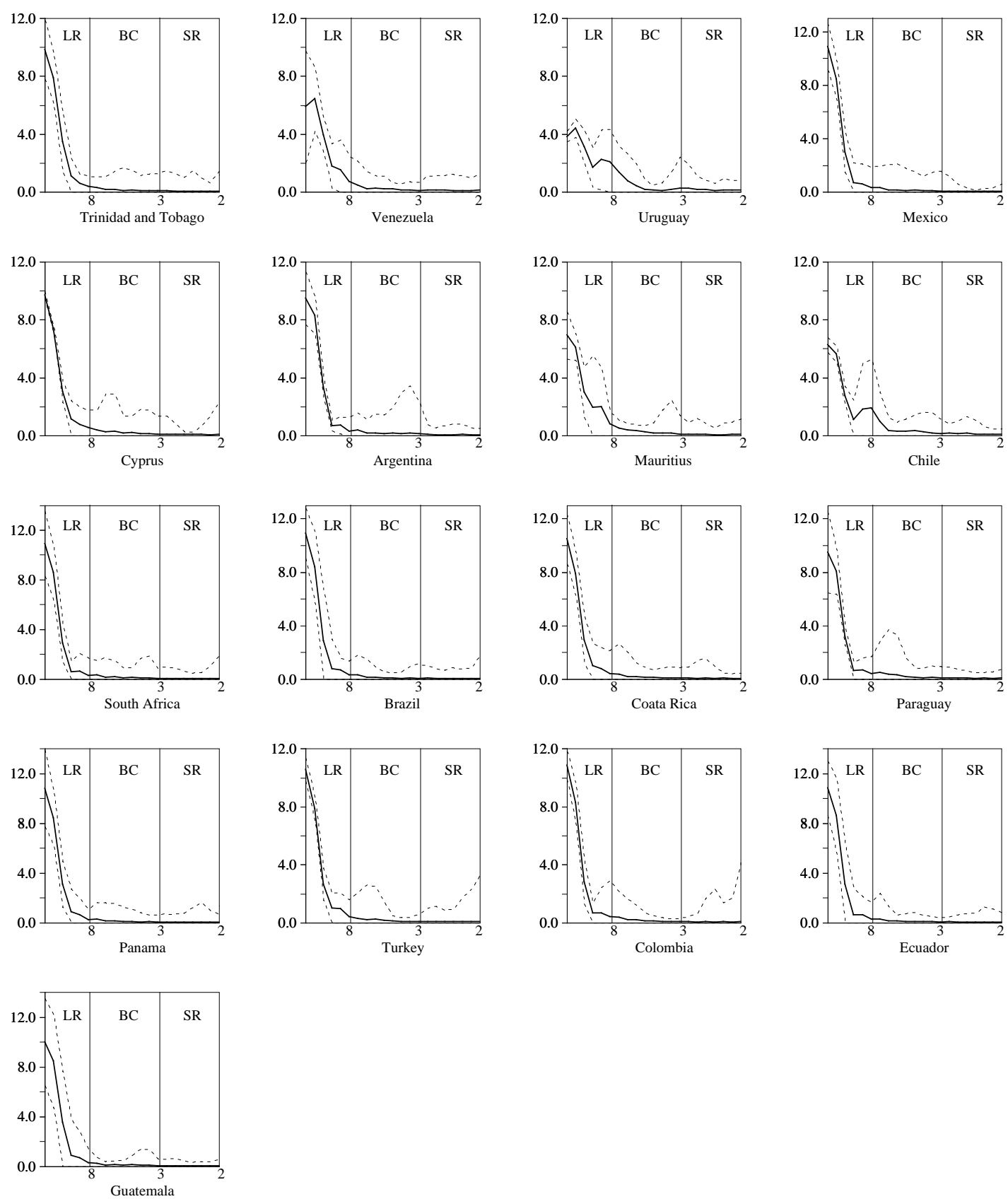

Figure 2. Estimated spectral densities of output, High-Income Developing Countries. The horizontal axis measures the cycle-length in years. The dotted lines form 95 percent confidence interval. $\mathrm{LR}=$ Long Run, $\mathrm{BC}=$ Business Cycle, and $\mathrm{SR}=$ Short Run . 

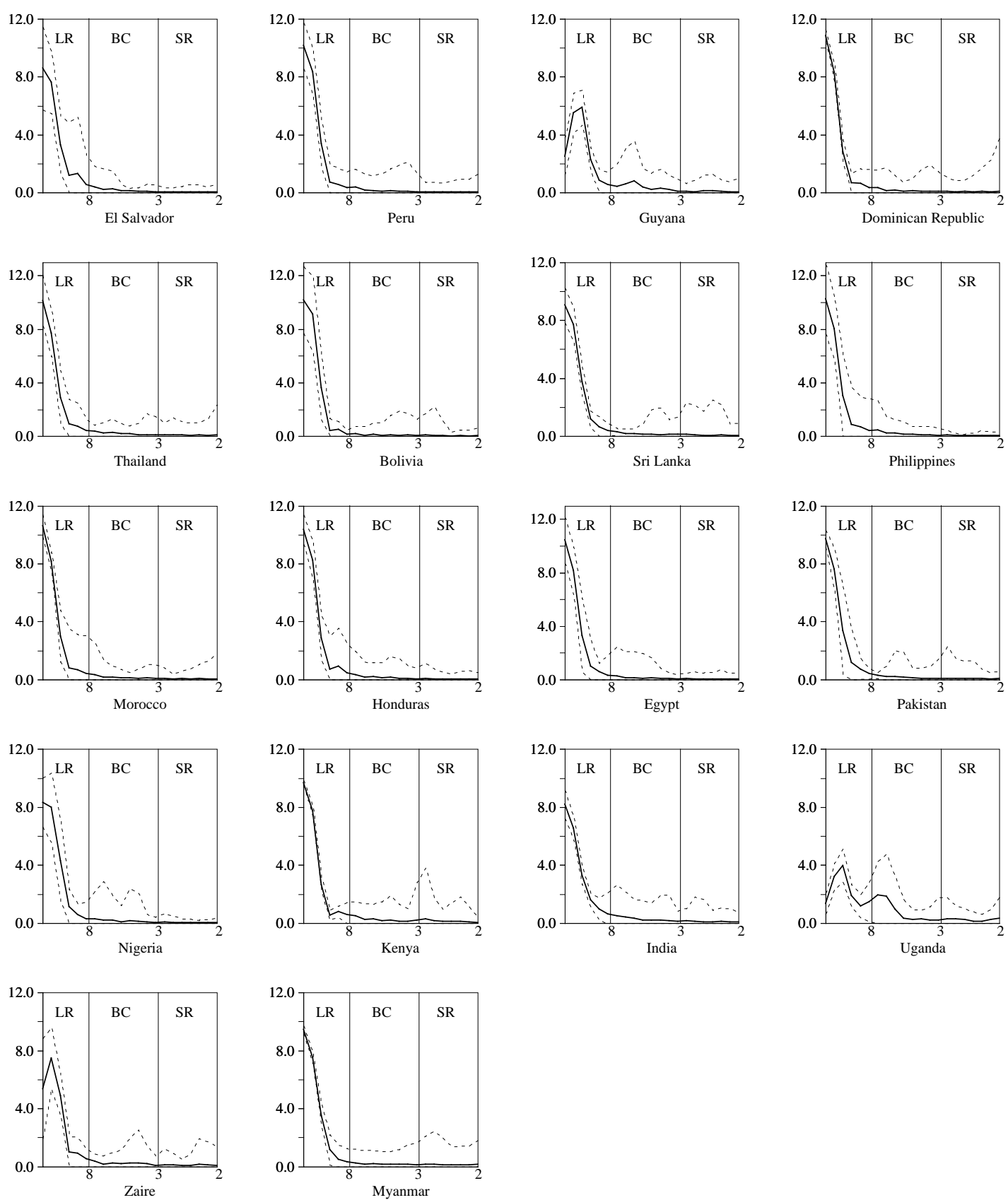

Figure 3. Estimated spectral densities of output, Low-Income Developing Countries. The horizontal axis measures the cycle-length in years. The dotted lines form 95 percent confidence interval. $\mathrm{LR}=$ Long Run, $\mathrm{BC}=$ Business Cycle, and $\mathrm{SR}=$ Short Run . 